\title{
A VISADA DO CONTEMPORÂNEO SOBRE A TRADIÇÃO: UMA TROCA DE OLHARES
}

Roberta Kelly Paiva

\section{RESUMO}

Pensar as tendências dos estudos contemporâneos sobre literatura implica, entre outras coisas, pensar o próprio conceito de contemporaneidade. Isto é, implica refletir sobre sua constituição histórica, características, preceitos teóricos e sua configuração na literatura. Em uma palavra, e por mais paradoxal que possa parecer, implica também pensar a tradição. É a essa reflexão teórica que convidamos o leitor.

PALAVRAS-CHAVE: contemporâneo; tradição; literatura.

"E não é provável que ele saiba o que será concebido, a menos que viva naquilo que não é apenas o presente, mas o momento presente do passado, a menos que esteja consciente, náo do que está morto, mas do que agora continua a viver."

T. S. Eliot ${ }^{1}$

o debruçarmo-nos sobre os estudos literários na nossa contemporaneidade, somos levados, em uma encruzilhada ou outra, a pensar a literatura como inserida em toda uma tradição cultural, e não apenas

1 ELIOT, T.S. "Tradição e talento individual”. In: Ensaios. Tradução de Ivan Junqueira. São Paulo: Art, 1989. p. 48. 
a pensar na própria e restrita tradição literária. Tal fato parece remeter-nos a uma série de questôes de ordem histórica, estética, filosófica e mesmo sociopolítica. Uma delas, no entanto, torna-se flagrante ao dirigirmos nosso olhar ao passado, do presente em que nos encontramos, e contrastarmos os artefatos culturais de nosso tempo aos produzidos outrora, bem como os de uma época remota àqueles de épocas passadas distintas, ou ainda de localidades (entenda-se: origens socioculturais) diversas. A questão, de todo modo, permanece latente: em que medida essa tradição cultural nos afeta ou, posto de outra forma, em que medida ela continua a ser contemporânea a nós? E, como uma via de mão dupla, em que medida a nossa própria contemporaneidade continua a interagir com os elementos dessa tradição e a transformá-la, ou reorganizá-la, segundo um ou outro grau, um ou outro parâmetro?

Se pudéssemos resumir tal problema a um só termo, concentraríamos nossa atenção, talvez - com Giorgio Agamben no texto "O que é o contemporâneo?”2 -, justamente no ser contemporâneo. Afinal, o tempo-chave de qualquer exercício comparativo situado no âmbito da nossa tradição cultural parece corresponder, de fato, à contemporaneidade. E esta alcança não somente a arte literária em si como manifestação cultural autêntica de todas as épocas e de todos os povos, mas, de igual maneira, as outras artes, cujo estudo - desde que dialogando com os estudos literários - pode ser inclusive abarcado pelo domínio da Literatura Comparada.

Portanto, nosso foco para a reflexão aqui proposta consistirá na abordagem teórica do enlace existente entre tradição cultural e contemporaneidade. $\mathrm{Ou}$, em outras palavras, consistirá na abordagem teórica dos confrontos e convergências entre esses dois elementos cujo cruzamento torna-se notável tanto para a literatura quanto para as outras artes. Trata-se, enfim, de uma tentativa de (re)descoberta a cada nova vez, visto que a tradição não está morta - como deixa entrever Didi-Huberman em Sobrevivência dos vaga-lumes ${ }^{3}$-, tampouco o ser contemporâneo está condenado à morte pelo simples anúncio do futuro e pelo abocanhamento do presente pelo passado a cada

2 AGAMBEN, Giorgio. "O que é o contemporâneo?" In: . O que é o contemporâneo e outros ensaios. Traduçáo de Vinícius Nicastro Honesko. Chapecó, Santa Catarina: Argos, 2009. p. 55-73.

3 DIDI-HUBERMAN, Georges. Sobrevivência dos vaga-lumes. Tradução de Vera Casa Nova e Márcia Arbex. Belo Horizonte: Ed. UFMG, 2011. 
instante que, uma vez perceptível, já se torna passado. A tradição, tal qual um vaga-lume, sobrevive e reluz.

O que torna a literatura de todas as épocas próxima a nós, nos dias de hoje? Talvez seja essa uma questão de fundo estético mais do que propriamente literário, visto que ela se amplia ao nível das artes em geral. Todavia, o que dela transparece em primeiro lugar é seu cunho histórico, já que evoca o jogo dialético entre presente e passado, remetendo-nos a uma posição de encruzilhada na história. Esta, por sua vez, longe de se restringir aos caminhos e descaminhos da humanidade seguidos por uma linha evolutiva, estende-se aos encontros de temporalidades e fronteiras que, de ilimitados, deixam sua marca registrada indefinidamente na memória cultural dos povos. Assim, o problema recoloca-se desta outra maneira, um pouco menos restrita à literatura: o que torna a arte, em seus diversos tipos e formas de manifestação, tão contemporânea a nós? $\mathrm{Ou}$, inversamente, o que nos torna tão contemporâneos a ela que, mesmo se advinda de tempos remotos, sensibiliza-nos a ouvir o que não cessa de nos dizer, a enxergar o que continua a nos mostrar?

Não é justamente esse também um dos fundamentos encontrados por Italo Calvino para ler os clássicos? Poderíamos tão somente parafrasear o questionamento anterior usando a seguinte de suas célebres teses sobre "por que ler os clássicos" - as quais, aliás, ressoam de imediato à nossa lembrança: "um clássico é um livro que nunca terminou de dizer aquilo que tinha para dizer"

Contudo, na mesma medida em que o problema aqui inicialmente levantado abre margem para se pensar a arte como um todo além da literatura em particular, ele extrapola os limites da preocupação com o cânone (seja literário, seja estético) e incorpora uma preocupação maior. Esta pôe em relevo o nosso papel, enquanto agentes produtores, receptores e acima de tudo transformadores da cultura, na constante atualização da tradição. Por isso, não se trata apenas de uma discussão em torno dos clássicos ${ }^{5}$; ela se concentra, antes, no modo como a tradição cultural faz-se contemporânea ao nosso tempo, ou no modo como nós a reatualizamos incessantemente.

Com efeito, a chave da nossa discussão parece esconder-se precisamente

4 CALVINO, Italo. "Por que ler os clássicos." In: Por que ler os clássicos. Tradução de Nilson Moulin. 2.ed. São Paulo: Companhia das Letras, 2005. p.11.

5 Ainda assim, as teses apontadas por Calvino servem-nos de brilhante inspiração. Não à toa, o volume que as reúne já se tornou, ele mesmo, um clássico entre nós. 
neste termo: o contemporâneo. E o que vem a ser, afinal, o contemporâneo? - perguntamo-nos junto com Giorgio Agamben, no esforço de acompanhar as reflexões do filósofo quando de uma lição inaugural proferida em Veneza em $2006^{6}$. A fim de adentrarmos a questão, cumpre primeiramente abrir mão de qualquer visão preconceituosa a respeito do tema, sobretudo aquela que o relaciona instantaneamente ao nosso presente último, conforme difundido pelo senso comum.

Falar de contemporaneidade não implica, necessariamente, falar de atualidade. Pode-se, inclusive, observar o contrário: quantas vezes flagramos marcas de um conservadorismo arraigado no discurso de políticos e intelectuais dos dias de hoje? Por outro lado, talvez também não devêssemos compreender o ser contemporâneo como ser absolutamente alienado ou alheio à realidade de sua própria época. É o que expressa igualmente Lionel Ruffel na introdução da recente publicação, acerca do mesmo tema, intitulada Qu'est-ce que le contemporain? ${ }^{7}$

Em seu ensaio, sob a idêntica denominação do livro, o autor problematiza a questão propondo simultaneamente outra indagação conexa e de aspecto mais preciso ou, quem sabe, um tanto impaciente - como ele próprio sugere, "[une question] toute à la fois irritante et légitime". Ela é formulada da seguinte maneira: a partir de quando, exatamente, situa-se o contemporâneo? E implica, conforme reconhece, um pressuposto que embasa a tradição do pensamento histórico e estético, qual seja o da periodização.

Embora o conceito pareça atraente à consideração do assunto, uma vez que traria à noção de contemporâneo uma localização cronológica confortadora, uma raiz na história, o crítico chama atenção para a ideia binária e maliciosa que se esconderia por trás de tal pressuposto: aquela que divide a trajetória da humanidade em um centro e suas periferias, em um polo dominador e os dominados, em um modelo de contemporaneidade e o resto do mundo,

6 Essa é a origem de seu texto indagador a começar pelo título, "O que é o contemporâneo?" - traduzido e publicado no Brasil em 2009 pela editora Argos (In: AGAMBEN. O que é o contemporâneo e outros ensaios. Tradução de Vinícius Nicastro Honesko. Chapecó, Santa Catarina: Argos, 2009. p. 55-73.)

7 RUFFEL, Lionel. “Qu'est-ce que le contemporain?” In: (org.). Qu'est-ce que le contemporain? Nantes: Cécile Defaut, 2010.

8 "[uma questão] a um só tempo irritante e legítima”. Tradução minha. 
que o seguiria. Ademais, conforme indica o autor, o problema da periodização envolve certo "presentismo" ou "presentificação" que faria corresponder o contemporâneo ao seu contemporâneo para aqueles que se debruçam sobre a inquirição de seu início quando, outrossim, pode-se argumentar que este sempre existiu para os que o reclamaram - e cita, entre outros, os exemplos de Diderot e Goethe, que já utilizavam o termo. Por outro lado, a generalização tampouco é satisfatória e, segundo Ruffel, devemos desconfiar de qualquer fórmula que preconize seu sentido anistórico ou atemporal. ${ }^{9}$ Dada, pois, a complexa natureza do contemporâneo, e recorrendo uma vez mais às teses de Italo Calvino:

Talvez o ideal fosse captar a atualidade como o rumor do lado de fora da janela, que nos adverte dos engarrafamentos do trânsito e das mudanças do tempo, enquanto acompanhamos o discurso dos clássicos, que soa claro e articulado no interior da casa. ${ }^{10}$

Contrapondo dessa forma às contingências do tempo presente a voz sempre inteligível dos clássicos - ainda que aparentemente abafada pelas novidades do momento, "como um reboar distante, fora do espaço invadido pelas atualidades"11 -, o escritor aponta, mesmo que indiretamente, o diálogo

9 Traçando um panorama do uso do termo "contemporâneo" e confrontando-o a "moderno", o autor reitera a sua precisa inserção na história do pensamento estético enquanto um "momento" da modernidade. Este, a seu ver, na condição do que chamamos de contemporaneidade, equivale a algo muito além da simples copresença ao transcorrer dos minutos, à passagem do tempo. Decorre, de acordo com ele, da emergência de desejos e da manifestação de usos que compóem a pauta da agenda histórica atual, da sociedade dita "pós-moderna". Envolve, assim, questóes de ordem política e econômica advindas das transformaçóes pós-Segunda Guerra Mundial, tais quais a democratização e massificação do acesso ao saber e à cultura, a multiplicação dos processos descentralizantes sob a corrente do multiculturalismo, bem como a emergência de estéticas contestatórias originárias sobretudo do momento pós-colonial da nossa pós-modernidade (para sermos apenas um pouco enfáticos). São essas algumas das questóes centrais que, na opiniâo do crítico, caracterizam a contemporaneidade. Para maiores explanaçôes, cf.: RUFFEL, Lionel. "Qu'est-ce que le contemporain?" Vox-poetica, <http://www.vox-poetica.org/t/articles/ruffel2010.html>, Acessado em 31/ 07/ 2012.

10 CALVINO, Italo. "Por que ler os clássicos." In: Por que ler os clássicos. Tradução de Nilson Moulin. 2.ed. São Paulo: Companhia das Letras, 2005, p. 15.

11 CALVINO, Italo. "Por que ler os clássicos." In: Por que ler os clássicos. Tradução de 
infindável da tradição com a contemporaneidade. Ora, o que são os clássicos senão a expressão viva e reluzente da tradição entre nós? De fato, esta pode ser-nos tão contemporânea quanto a última das tendências que influenciam a sociedade, ou até mais, na medida em que lhe for mais relevante. Entretanto, a relação entre ambas - isto é, entre a tradição, e especificamente a tradição cultural, e a contemporaneidade - revela-se de todo peculiar, dado que a própria constituição desse ser contemporâneo não é, como já pressentimos, tão elementar.

Agamben inicia sua explanação acerca desse estado de ser pelo seu anacronismo, e evoca Roland Barthes, o qual já postulava em referência a um pensador alemão: "o contemporâneo é o intempestivo"12. Friedrich Nietzsche, então jovem quando publicara o volume de suas Consideraçóes Intempestivas (1876), demonstrou sua qualidade de pensador "verdadeiramente contemporâneo", no entender agambeniano, ao assumir uma postura crítica sobre o mal que, segundo ele, afetava sua época. Consistia esse na "cultura histórica" da qual a sociedade de seu tempo se orgulhava ou, conforme acreditava, na "febre da história" que nos devoraria a todos.

De tal postura advém o que o filósofo italiano considera um anacronismo exemplar: essa espécie de deslocamento, discronia, desconexão e dissociação - para empregar seus termos - permite ao sujeito descolar-se de sua realidade última e irremediável. Possibilita-lhe dela tomar certa distância, desvencilhar-se de suas tramas a fim de melhor contemplá-la e, assim, a ela ajustar-se. Estaria ele cônscio, porém, de que esse ajuste nunca se exprimiria por uma coincidência perfeita com seu tempo, uma vez que lhe é impossível assimilá-lo por completo, guardando diante dele, nesse sentido, sempre algo de inatual.

Como nos esclarece Douglas Kellner ${ }^{13}$, tal postura assumida por Nietzsche deriva sobretudo de suas ideias de renovação cultural. Urgia, para ele,

Nilson Moulin. 2.ed. São Paulo: Companhia das Letras, 2005, p. 15.

12 Cf.: AGAMBEN, Giorgio. "O que é o contemporâneo?” In: O que é o contemporâneo e outros ensaios. Tradução de Vinícius Nicastro Honesko. Chapecó, Santa Catarina: Argos, 2009. p. 58.

13 KELLNER, Douglas. "A crítica de Nietzsche à cultura de massa." Revista Famecos: midia, cultura e tecnologia, 13: 12-22, Porto Alegre, dez. 2000. [Disponível em: Revista Famecos, http://revistaseletronicas.pucrs.br/ojs/index.php/revistafamecos/article/viewFile/3078/2355, Acessado em 04/ 07/ 2012.] 
conter a onda degradante do pensamento europeu moderno, desencadeada pela cultura de massas predominante que ameaçava, a seus olhos, o futuro alemão. Pela repetição de padrôes e modelos sociais que mais representava, a seu ver, um esvaziamento de sentidos na vida do homem moderno, o ainda jovem pensador revolucionário enxergava na acumulação de conhecimento histórico a causa de sua paralisia bem como da falta de criatividade da sociedade tida por ele como bárbara. Disso decorre sua aversão à crença geral na história e seu anseio por difundir a valorização do presente, a esperança no momento atual, que poderia reconfigurar as perspectivas de futuro.

Ou seja, sendo integrante da mesma sociedade "bárbara" e envolto por sua cultura massificada, o jovem alemão opta, todavia, por se colocar na contramão das massas, literalmente em uma posição de discronia (de anti-historicidade) ou desconexão em relação à sua época. $\mathrm{O}$ curioso é que esse combate à assim chamada "febre da história" venha justamente de quem, lutando contra os valores disseminados em seu tempo, e por isso mesmo sendo dele contemporâneo - se concordamos com Agamben -, não consegue a ele aderir plenamente renegando, porém, a importância do passado e insistindo em agarrar-se ao presente. Não haveria em tal atitude algo de paradoxal?

Tomemos o exemplo de Nietzsche - mencionado por Agamben logo no início de seu ensaio - como inspiração para refletirmos exatamente sobre esse entrelaçamento entre a história e a atualidade ou, se preferirmos, entre a tradição e a contemporaneidade. Se esta se compóe apenas das inovaçóes e mudanças ocasionadas pelo presente, como perceber suas contribuiçóes ou atribuir-lhes algum grau de relevância desconsiderando suas raízes e suas mais profundas motivações? Como prescindir da história para explicar a realidade atual, ou no mínimo interpretá-la, ao lançar luz sobre suas obscuridades?

E são tais obscuridades - comparadas a "trevas do presente" - frisadas por Agamben justamente como a contraparte da contemporaneidade. Aliás, talvez seja a incoerência de negligenciar o conhecimento histórico que o filósofo italiano permite-nos depreender de seu raciocínio, ao defender que o homem contemporâneo é aquele que fita a realidade de sua época com o intuito de dela captar não a luminosidade - a qual por vezes pode ofuscar a visão do observador -, mas o escuro, a sombra, as trevas que a penetram. São elas, no entender agambeniano, que o sujeito não deve perder de vista ao encarar o seu século. Afinal, conforme assevera, 
contemporâneo é aquele que percebe o escuro do seu tempo como algo que lhe concerne e náo cessa de interpelá-lo, algo que, mais do que toda luz, dirige-se direta e singularmente a ele. Contemporâneo é aquele que recebe em pleno rosto o facho de trevas que provém do seu tempo. ${ }^{14}$

Acaso não estaríamos a ler aqui, nas entrelinhas, o papel das dobras da história - em uma palavra, da tradição - para a contemporaneidade? Ora, se o exemplo de Nietzsche reflete, para Agamben, o perfil desse ser contemporâneo que não se deixa cegar pelas luzes - ou holofotes da cultura massificada - de sua era e consegue dela tomar a devida distância que lhe permite tentar compreendê-la e criticá-la, como pode ele dar de si mesmo tamanho testemunho anti-histórico? Como é possível enxergar no presente as sombras que ele oculta senão buscando sua origem no passado, de onde elas são projetadas ou introjetadas na história? Paradoxal ou não, o testemunho nietzschiano, assim intempestivo, sugere-nos, de todo modo, que o defrontar-se com o próprio século traduz-se pela postura ativa de quem se recusa a ser ofuscado pelas suas luzes e procura descobrir nele o que se esconde na penumbra, por trás de seus refletores.

É Georges Didi-Huberman, um crítico de nós mais próximo no tempo, quem nos fala justamente do contraste entre luz e sombra na esteira da tradição. Em Sobrevivência dos vaga-lumes ${ }^{15}$, a metáfora por ele operacionalizada - a da pulsação intermitente do vaga-lume - representa uma forma particular de articular momentos, temporalidades, experiências capazes de entrelaçar não só o passado ao presente, como também este ao futuro. E, tomando o exemplo de outra personalidade que, nos moldes agambenianos, seria a perfeita encarnação do sentimento de contemporaneidade, retrata-nos a sua luta - efetivamente levada a cabo e subitamente interrompida pelo seu assassínio em 1975 - contra os grandes projetores da então reinante cultura massificada de sua era.

14 AGAMBEN, Giorgio. "O que é o contemporâneo?" In: O que é o contemporâneo e outros ensaios. Traduçáo de Vinícius Nicastro Honesko. Chapecó, Santa Catarina: Argos, 2009. p. 64.

15 DIDI-HUBERMAN, Georges. Sobrevivência dos vaga-lumes. Tradução de Vera Casa Nova e Márcia Arbex. Belo Horizonte: Ed. UFMG, 2011. 
Trata-se de Pier Paolo Pasolini, revolucionário cineasta italiano que tentava combater, inclusive (quiçá principalmente) por meio de sua arte, a barbárie totalitária do capitalismo e do moderno padrão de consumo. Estes engendravam, a seu ver, um genocídio cultural motivado pelo neofascismo televisual e pelo esvaziamento do humano, a que todos estariam irremediavelmente submetidos após a Segunda Grande Guerra. Contudo, se para o revolucionário o futuro da humanidade já estaria lamentavelmente comprometido, Didi-Huberman revela-nos exatamente o fulgor do brilho dos vaga-lumes que sempre encantou a visão e a imaginação do cineasta, sobretudo quando ainda jovem, assim como sua potência ressurgente. $\mathrm{O}$ que representaria, pois, essa potência ressurgente, esse contínuo re(des)aparecer dos vaga-lumes, esse jogo intermitente de luz e sombra no desenrolar da história, senão a sobrevida de algo que resta e que vem à tona a cada novo instante pelos agenciamentos memorialísticos que fazem renascer no presente fragmentos do passado e que, de forma similar, projetam-nos para um futuro?

Esta é a imagem reluzente dos vaga-lumes: o que permanece entre a cultura e a história não é apagado para sempre, mas jaz na memória coletiva, a qual, vez ou outra, o faz transparecer sob um novo brilho, como um espectro que, naturalmente inconstante, desaparecerá para tornar a surgir com força e intensidade renovadas. E é essa também a imagem da tradição vista da contemporaneidade. Só é capaz de perceber seu brilho intermitente quem, estando imerso na ofuscante realidade do presente, dela se distancia o suficiente para enxergar a noite escura que a circunda. É então que, nesse espaço de abertura aos possíveis, "dos apesar de tudo" - como reitera Didi-Huberman ${ }^{16}$ -, os lampejos dos vaga-lumes ou os clarôes erráticos da tradição tornam-se aparentes aos olhos de quem se permite ser dela contemporâneo.

E, afinal, o que significa ser contemporâneo da tradição, e o que isso implica para o nosso entendimento da história das artes - para não dizer da cultura em geral - ou, especificamente, da literatura? Ora, ao atinarmos para o sentido histórico da tradição, conforme já salientava T. S. Eliot em seu “Tradição e talento individual" (1919), damo-nos conta de que ela se encontra bem mais próxima da contemporaneidade em sua essência do que poderíamos

16 DIDI-HUBERMAN, Georges. Sobrevivência dos vaga-lumes. Tradução de Vera Casa Nova e Márcia Arbex. Belo Horizonte: Ed. UFMG, 2011. p. 42. 
supor. De acordo com o poeta e ensaísta inglês, "o sentido histórico implica a percepção, não apenas da caducidade do passado, mas de sua presença" ${ }^{17}$.

Essa mesma latência do passado no presente pode ainda ser compreendida inversamente, como uma via de mão dupla, se considerarmos, desta vez com Walter Benjamin, que o sentido histórico implica igualmente a percepção de um passado prenhe de "presentes". Para evocar seus próprios termos, "a história é objeto de uma construção cujo lugar não é o tempo homogêneo e vazio, mas um tempo saturado de 'agoras'"18.

Portanto, sendo a história concebida antes como uma rede de temporalidades do que como uma linha cronológica baseada em uma ideia unitária de tempo, as noçóes de tradicional e contemporâneo passam a ser assimiladas no cruzamento do temporal com o atemporal. Isso significa, por conseguinte, que ser contemporâneo da tradiçáo é saber enxergar no passado não apenas a origem - a arké, como lembra Agamben -, mas reflexos do presente; e vice-versa, é saber distinguir neste as marcas do arcaico. Assim sintetiza o italiano:

De fato, a contemporaneidade se escreve no presente assinalando-o antes de tudo como arcaico, e somente quem percebe no mais moderno e recente os índices e as assinaturas do arcaico pode dele ser contemporâneo. Arcaico significa: próximo da arké, isto é, da origem. [...] A distância - e, ao mesmo tempo, a proximidade - que define a contemporaneidade tem o seu fundamento nessa proximidade com a origem, que em nenhum ponto pulsa com mais força do que no presente. ${ }^{19}$

Logo, o fundamento desse ser contemporâneo que aqui procuramos apreender revela-se não menos paradoxal que a figura anti-histórica de Nietzsche,

17 ELIOT, T.S. "Tradição e talento individual". In: Ensaios. Tradução de Ivan Junqueira. São Paulo: Art, 1989. p. 39.

18 BENJAMIN, Walter. "Sobre o conceito da história." In: Magia e técnica, arte e politica: ensaios sobre literatura e história da cultura. Traduçáo de Sérgio Paulo Rouanet. 7.ed. São Paulo: Brasiliense, 1994. p. 229. (Obras escolhidas, v. 1)

19 AGAMBEN, Giorgio. "O que é o contemporâneo?" In: O que é o contemporâneo e outros ensaios. Tradução de Vinícius Nicastro Honesko. Chapecó, Santa Catarina: Argos, 2009. p. 69. 
cujo testemunho apresenta-se, porém, ao menos no entender agambeniano, caracteristicamente contemporâneo. Próximo e simultaneamente distante da origem, do fundo do arcaico; o "ainda não" e o "não mais" que configuram o "agora" (o kairos) inapreensível da moda - de que Agamben se serve como ilustração em seu texto. Tal é o "agora" da contemporaneidade: igualmente indefinível, não identificável cronometricamente, tampouco localizável em um "a partir de quando" (como alude Lionel Ruffel ${ }^{20}$ )... Antes, localizável, sim, em uma experiência do limiar, do despontar benjaminiano das reminiscências, do residual, da parte do não vivido de todo o vivido, da fratura do século, do ponto de cesura na história que refrata o passado e insere no tempo uma descontinuidade. Essa experiência particular, "apesar de tudo" - para evocar ainda Didi-Huberman ${ }^{21}$-, cria uma relação especial entre os tempos, possibilitando-nos, conforme sublinha Agamben, reatualizar continuamente o passado e, pela sua interpolação na linearidade histórica, projetar o futuro transformando o presente. Acaso seria essa a quimera perseguida por Nietzsche?

Para citar uma vez mais nosso filósofo tão contemporâneo: "É como se aquela invisível luz, que é o escuro do presente, projetasse a sua sombra sobre o passado, e este, tocado por esse facho de sombra, adquirisse a capacidade de responder às trevas do agora. ${ }^{22}$ " Isso não corresponde exatamente ao que já professava Eliot? Tomando emprestados os termos do poeta, quem quer que tenha aceitado também essa ideia não poderá julgar absurdo "que o passado

20 RUFFEL, Lionel. "Qu'est-ce que le contemporain?” Vox-poetica, <http://www.vox-poetica. org/t/articles/ruffel2010.html>, Acessado em 31/ 07/ 2012.

21 Talvez caiba aqui relembrar as exatas palavras do crítico contra o pessimismo de Pasolini referente à "máquina totalitária” capitalista e cujo rumo seguiria uma marcha apocalíptica: "Assujeitou-se o mundo, assim, totalmente como o sonharam [...] nossos atuais 'conselheiros pérfidos'? Postulá-lo é, justamente, dar crédito ao que sua máquina quer nos fazer crer. É ver somente a noite escura ou a ofuscante luz dos projetores. É agir como vencidos: é estarmos convencidos de que a máquina cumpre seu trabalho sem resto nem resistência. É não ver mais nada. É, portanto, não ver o espaço - seja ele intersticial, intermitente, nômade, situado no improvável - das aberturas, dos possíveis, dos lampejos, dos apesar de tudo." (DIDI-HUBERMAN, Georges. Sobrevivência dos vaga-lumes. Tradução de Vera Casa Nova e Márcia Arbex. Belo Horizonte: Ed. UFMG, 2011. p. 42.)

22 AGAMBEN, Giorgio. "O que é o contemporâneo?” In: O que é o contemporâneo e outros ensaios. Tradução de Vinícius Nicastro Honesko. Chapecó, Santa Catarina: Argos, 2009. p. 72. 
deva ser modificado pelo presente tanto quanto o presente esteja orientado pelo passado" 23 .

Ora, não estamos aqui a todo momento a nos referir - seja consciente seja inconscientemente - ao célebre jogo dos precursores imortalizado por Jorge Luis Borges? Ele - que afirma, em "Kafka e seus precursores" (1951), a imprescindibilidade da palavra "precursor" para o vocabulário crítico - é quem nos mostra como as idiossincrasias de Kafka presentes em seus antecessores só são perceptíveis aos nossos olhos após conhecermos na modernidade a monumental obra do ficcionista alemão; do contrário, elas nem mesmo existiriam (para nós). Vale dizer: se cada escritor tem o poder de criar seus precursores - como acentua Borges - ou de inserir-se no presente tanto quanto presentifica o passado, alterando a ordem das coisas - como acentua Eliot -, cabe ao leitor operar a sua significação. Isto é, compete à sua leitura desvendar como o escritor (no caso da literatura) ou o artista modifica os sentidos constituídos para instaurar novos, como reorganiza o cânone, como rearranja os elementos da tradiçáo, como, enfim, ele "modifica nuestra concepción del pasado, como ha de modificar el futuro" 24 . Eis a lição do mestre argentino, nosso eterno contemporâneo.

Talvez não seja demais tornar a evocar Calvino em uma de suas teses: "É clássico aquilo que persiste como rumor mesmo onde predomina a atualidade mais incompatível." Ou ainda nesta outra: "Os clássicos são aqueles livros que chegam até nós trazendo consigo as marcas das leituras que precederam a nossa e atrás de si os traços que deixaram na cultura ou nas culturas que atravessaram" 25 . Tudo isso para dizer, por fim, que a imbricação que une tradição e contemporaneidade encontra-se não tanto nos desdobramentos factuais, temporais ou objetivos da história quanto nos nossos próprios olhos, na agudeza do olhar ou na nossa capacidade de enxergar. É assim que possibilitamos que a tradição cultural seja de nós eternamente contemporânea, e é assim que nos fazemos contemporâneos a ela, deixando sua herança ressoar

23 ELIOT, T. S. "Tradição e talento individual". In: Ensaios. Tradução de Ivan Junqueira. São Paulo: Art, 1989. p. 40.

24 "modifica nossa concepção do passado, como há de modificar o futuro" (BORGES, Jorge Luis. "Kafka y sus precursores." In: . Otras inquisiciones, Obras completas. v. 2. Buenos Aires: Emecé Editores, 1974. p. 90.) Tradução minha.

25 CALVINO, Italo. "Por que ler os clássicos." In: . Por que ler os clássicos. Tradução de Nilson Moulin. 2. ed. São Paulo: Companhia das Letras, 2005. p. 15 e 11 (respectivamente). 
continuamente em nossos ouvidos e sendo sensíveis o bastante para perceber sua luminosidade, mesmo que intermitente, como o brilho dos vaga-lumes.

É da capacidade de colocar o arcaico lado a lado com o moderno, o passado em relação com o agora e em proximidade com o futuro que dependerá - parafraseando Agamben ${ }^{26}$ - o nosso entendimento da história da cultura e da rede de temporalidades que entrelaça suas diversas manifestaçóes artísticas, inclusive a literatura. Dela dependerá também nossa abertura para conceber, em um domínio abrangente como o da Literatura Comparada, a possibilidade de refletir não apenas sobre o cruzamento de tais temporalidades como ainda sobre o diálogo das variadas formas artísticas entre si, expressas, por seu turno, sob variados tipos de manifestação que perpassam a história cultural da humanidade. Deixemos, por ora, o debate em pauta, e esperemos o lampejo do próximo vaga-lume...

\title{
LA VISÉE DU CONTEMPORAIN SUR LA TRADITION: UN ÉCHANGE DE REGARDS
}

\begin{abstract}
RÉSUMÉ
Penser les tendances des études contemporaines sur la littérature implique, entre autres choses, penser le concept de contemporanéité même. C'est-à-dire, réfléchir sur sa constitution historique, ses traits, ses aspects théoriques et sa configuration dans la littérature. En un seul mot, pour plus paradoxal que ce soit, implique aussi penser la tradition. C'est à une telle réflexion théorique qu'on invite le lecteur.
\end{abstract}

MOTS-CLÉ: contemporain; tradition; littérature.

Recebido em: 09/05/2012

Aprovado em: 10/12/2012

26 AGAMBEN, Giorgio. "O que é o contemporâneo?" In: O que é o contemporâneo e outros ensaios. Traduçáo de Vinícius Nicastro Honesko. Chapecó, Santa Catarina: Argos, 2009. p. 72-73. 